\title{
Short communication: Effects of diets containing supplemental fats on ruminal fermentation and milk odd- and branched-chain fatty acids in dairy cows
}

\author{
M. Vazirigohar, ${ }^{*} \dagger^{1}$ M. Dehghan-Banadaky, ${ }^{\text {} ~ K . ~ R e z a y a z d i, ~}{ }^{*}$ A. Nejati-Javaremi, ${ }^{*}$ H. Mirzaei-Alamouti, $\ddagger$ \\ and A. K. Patra§ ${ }^{1}$ \\ *Department of Animal Science, College of Agriculture and Natural Resources, University of Tehran, Alborz, Iran 31587-77871 \\ †Zist Dam Group, Alborz, Iran, 31476-66544 \\ ‡Department of Animal Science, University of Zanjan, Zanjan, Iran 45371-38791 \\ §Department of Animal Nutrition, West Bengal University of Animal and Fishery Sciences, 37 K. B. Sarani, Belgachia, Kolkata, India 700037
}

\begin{abstract}
There is a growing interest in odd- and branchedchain fatty acids (OBCFA) in milk following reports that several branched-chain fatty acids (FA) have health promoting effects, and certain milk OBCFA could serve as a biomarker to assess ruminal function. Twenty-four Holstein cows were fed 3 low-forage diets containing $30 \mathrm{~g} / \mathrm{kg}$ of dry matter of prilled palm fat (PPF), sunflower oil (SO), or an equal mixture of both fats (experiment 1) or 3 diets containing $30 \mathrm{~g} / \mathrm{kg}$ of dry matter of $\mathrm{SO}$ with a forage-to-concentrate ratio of 39:61, 44:56, or 48:52 (Experiment 2); diets were fed to investigate milk OBCFA composition and to explore the relationships between ruminal VFA and milk OBCFA using principal component analysis. Including SO in diets decreased yields of milk 13:0 anteiso, 15:0 anteiso, 15:0, 17:0, cis-9 15:1, and cis-9 17:1 compared with PPF. The molar proportion of ruminal propionate was the lowest and the yields of milk 14:0 iso and 16:0 iso were the greatest with the diet containing both fat supplements. Replacing concentrate with forages linearly increased ruminal acetate and yields of milk 13:0 iso, 14:0 iso, 15:0 iso, 16:0 iso, 17:0 iso, 13:0 anteiso, 15:0 anteiso, 15:0, 17:0, cis-9 15:1, and cis-9 17:1. The principal component analysis revealed that ruminal molar proportion of acetate related to concentrations of milk iso FA containing $<17$-carbon, whereas ruminal propionate related to milk 15:0, 17:0, cis-9 15:1, and cis-9 17:1, with the stronger correlations between milk OBCFA and ruminal acetate than propionate. No associations were found between ruminal molar propor-
\end{abstract}

\footnotetext{
Received November 23, 2017.

Accepted March 8, 2018.

${ }^{1}$ Corresponding authors: mvaziri@ut.ac.ir and patra_amlan@ yahoo.com
}

tion of butyrate and milk OBCFA concentrations. The results suggest that complete replacement of PPF with $\mathrm{SO}$ at $30 \mathrm{~g} / \mathrm{kg}$ of dry matter in low-forage diets is not an effective strategy to enhance bioactive branchedchain FA in milk, rather this feeding practice lowers anteiso FA in milk; however, increasing forage proportion in diets containing $\mathrm{SO}$ enhances several iso and anteiso FA in milk. The milk OBCFA concentrations have stronger correlations with ruminal acetate molar proportion than with propionate or butyrate in cows fed diets containing supplemental fats.

Key words: forage proportion, iso and anteiso fatty acid, palm fat, sunflower oil, volatile fatty acid

\section{Short Communication}

Fat supplements are often added to the diets of lactating cows to increase energy concentration and milk production. Fats rich in SFA increase SFA concentrations in milk (Lock et al., 2013). Inclusion of unsaturated fat sources in the diets lowers SFA and enhances UFA in milk, and those rich in 18:2n-6 and 18:3n-3 are the most effective to increase cis-9,trans-11 CLA (Shingfield et al., 2013), which improves concentrations of health promoting fatty acids (FA) in milk. Interest has been growing in enriching ruminant-derived foods with branched-chain FA, because several iso and anteiso FA have shown many beneficial effects, including inhibition of the growth of several cancer cell lines in vitro and maintenance of enterocyte health (Ran-Ressler et al., 2014).

Milk fat branched-chain FA originate principally from the digestion and absorption of ruminal microbial lipids (Fievez et al., 2012). Changes in milk branched-chain FA in response to fat supplements are not well characterized; however, fat supplementation may change these milk FA (Baumann et al., 2016) via modifying the ruminal microbial populations (Bayat et 
al., 2018). Moreover, the magnitude of responses likely depends on amount, form, and FA profile of dietary fats and the composition of basal diets. Dietary inclusion of plant oils rich in 18:2n-6 reduced concentrations of several iso and anteiso FA in milk in grass silage diets (Halmemies-Beauchet-Filleau et al., 2011), but not in mixture of corn silage and grass silage diets (AlfonsoAvila et al., 2017). One potential strategy to enhance branched-chain FA, in particular iso FA, in milk is increasing dietary forage proportion (Fievez et al., 2012; Patel et al., 2013); however, examining forage level in diets containing fat supplements on these FA in milk is limited (Saliba et al., 2014).

Milk odd- and branched-chain FA (OBCFA) have been used to predict the molar proportions of individual ruminal VFA as a noninvasive tool to assess ruminal fermentation function (Bhagwat et al., 2012); however, some reports do not completely support application of milk OBCFA to estimate ruminal VFA due to postruminal modification of OBCFA composition (French et al., 2012; Vlaeminck et al., 2015). It has been indicated that iso FA and straight odd-chain FA in milk have positive correlations with ruminal acetate and propionate, respectively (Fievez et al., 2012); however, the associations between ruminal fermentation pattern and milk OBCFA composition have not been well examined for diets containing fat supplements.

The purpose of our study was to evaluate the effects of substituting a saturated with an unsaturated fat supplement in low-forage diets on branched-chain FA in milk; however, it is well established that inclusion of unsaturated fat in high-concentrate diets induces milk fat depression (Harvatine et al., 2009). Therefore, the other aim of our study was to examine increasing forage proportions in diets containing a supplemental unsaturated fat as a potential strategy to simultaneously recover milk fat depression and to enhance health beneficial FA in milk including branched-chain FA secretions. It was hypothesized that milk OBCFA could be altered due to modifications of ruminal microbial populations by dietary supplemental fats and forage proportions. We examined the effects of replacement of a saturated fat-enriched 16:0 (prilled palm fat; PPF) with an unsaturated fat rich in 18:2n-6 (sunflower oil; SO) in low-forage diets (experiment 1) or increasing the forage-to-concentrate ratio $(\mathbf{F}: \mathbf{C})$ in diets containing SO (experiment 2) on ruminal fermentation characteristics and milk OBCFA composition. The dietary effects on feed intake, digestibility, milk production and composition, and milk FA composition, except OBCFA, were reported previously (Vazirigohar et al., 2014). Moreover, data from both experiments were used to explore the associations among ruminal VFA and milk
OBCFA in cows fed diets containing supplemental fats using principal component analysis (PCA).

All experimental procedures were approved by the Animal Experiment Committee of the University of Tehran (Alborz, Iran). Twenty-four multiparous Holstein cows from the Dairy Research Farm of the University of Tehran were used in experiment 1 (mean $\pm \mathrm{SD} ; 618 \pm 9.19 \mathrm{~kg}$ of BW, $3.2 \pm 0.22$ parity, $90 \pm$ $6.04 \mathrm{DIM}$, and $35.8 \pm 0.88 \mathrm{~kg}$ of milk/d). Experiment 2 started after a 14-d washout period using 19 out of 24 cows recruited from experiment 1 and 5 additional cows $(619 \pm 15.1 \mathrm{~kg}$ of BW, $3.0 \pm 0.24$ parity, $107 \pm$ $6.22 \mathrm{DIM}$, and $35.5 \pm 0.89 \mathrm{~kg}$ of milk/d). During the washout period, all cows received a TMR containing alfalfa hay and corn silage (5:4 wt/wt; on DM basis), concentrate (F:C of 39:61; on DM basis), and $18 \mathrm{~g} / \mathrm{kg}$ of DM of PPF. Cows in each experiment were blocked by DIM and then allocated to treatments according to a randomized complete block design with 3-d baseline, 18-d adaptation, and 7-d measurement periods (total 25-d experimental period). Treatments in experiment 1 consisted of low-forage (F:C of 39:61, DM basis) diets containing $30 \mathrm{~g} / \mathrm{kg}$ of DM of either (1) PPF (fractionated refined palm oil; RumiFat R100 from Ecolex, Selangor, Malaysia), (2) SO (refined SO; Oila-Golrang Pakhsh Co., Tehran, Iran), or (3) an equal mixture of both fats (Table 1). Treatments in experiment 2 consisted of either (1) low-forage (F:C of 39:61), (2) medium-forage ( $\mathrm{F}: \mathrm{C}$ of $44: 56)$, or (3) high-forage (F:C of 48:52) diets containing $30 \mathrm{~g} / \mathrm{kg}$ of DM of SO (Table $1)$. Cows were housed in individual tiestalls with ad libitum access to water and milked thrice daily (0100, 1000, and $1700 \mathrm{~h}$ ). The TMR was offered daily as equal meals at 0800 and $1600 \mathrm{~h}$ ensuring ad libitum intakes (i.e., $10 \%$ orts as fed).

Samples of milk (without preservative) were collected at each milking on d 19, 21, and 23 of each experiment, and stored at $-20^{\circ} \mathrm{C}$ until analysis of FA. Samples of ruminal fluid were collected on d 25 within 3 to $5 \mathrm{~h}$ after morning feeding using a stomach tube attached to an Erlenmeyer flask connected to a vacuum pump. An initial $200 \mathrm{~mL}$ of ruminal fluid sample was discarded to minimize salivary contamination. After collection (300-mL sample), samples were filtered through 4 layers of cheesecloth and $\mathrm{pH}$ was determined immediately using a portable pH-meter (827 pH Lab; Metrohm AG, Herisau, Switzerland). A 10-mL aliquot of the filtered ruminal fluid was acidified with $1 \mathrm{~mL}$ of $50 \%$ metaphosphoric acid and stored at $-20^{\circ} \mathrm{C}$ for VFA analysis. Ruminal fluid samples were collected on the last day of each experiment, after completing the collection of milk samples, to avoid potential effects of stress on cows and consequently on the validity of milk FA composition. 
Ruminal fluid collection using oro-ruminal probe was permitted 1 time per experiment because we used highproducing lactating cows.

For FA analysis, milk samples of each cow (i.e., 9 samples/cow) were pooled on a milk yield basis after thawing at $38^{\circ} \mathrm{C}$ in a water bath. Milk FA concentrations were determined according to standard procedures (Halmemies-Beauchet-Filleau et al., 2011). Briefly, lipid in milk samples was extracted using a mixture of ammonia, ethanol, diethyl ether, and hexane, and transesterified to FAME using methanolic sodium methoxide as a catalyst. Milk FAME were quantified using a gas chromatograph (model 6890; Hewlett-Packard, Wilmington, DE) equipped with a flame-ionization detector, an automatic injector, a split injection port, and a 100-m fused silica capillary column (CP-SIL; Chromopack 7489, Middelburg, the Netherlands) using a temperature gradient program and hydrogen as a carrier gas. Peaks were identified by comparing retention times with FAME standards (Sigma-Aldrich, St. Louis, $\mathrm{MO}$ ). Identification of FA was verified based on GC-MS analysis of 4,4-dimethyloxazoline derivatives prepared from FAME. Milk FA composition was expressed as a weight percentage of total FA using theoretical relative response factors.

The ruminal fluid samples were thawed and $400 \mu \mathrm{L}$ of supernatant and $100 \mu \mathrm{L}$ of 4-methylvaleric acid (50 $\mathrm{mmol} / \mathrm{L}$; Sigma-Aldrich) as an internal standard were

Table 1. Ingredients and chemical composition of experimental diets

\begin{tabular}{|c|c|c|c|c|c|c|}
\hline \multirow[b]{2}{*}{ Item } & \multicolumn{3}{|c|}{ Experiment $1^{1}$} & \multicolumn{3}{|c|}{ Experiment $2^{2}$} \\
\hline & LF-P & LF-PS & LF-S & LF-S & MF-S & $\mathrm{HF}-\mathrm{S}$ \\
\hline \multicolumn{7}{|l|}{ Ingredient $(\mathrm{g} / \mathrm{kg}$ of $\mathrm{DM})$} \\
\hline Alfalfa hay & 217 & 217 & 217 & 217 & 247 & 276 \\
\hline Corn silage & 174 & 174 & 174 & 174 & 189 & 205 \\
\hline Ground barley & 260 & 260 & 260 & 260 & 203 & 146 \\
\hline Ground corn & 52 & 52 & 52 & 52 & 42 & 31 \\
\hline Molassed beet pulp & 69 & 69 & 69 & 69 & 65 & 59 \\
\hline Wheat bran & - & - & - & - & 28 & 58 \\
\hline Corn gluten meal & 11 & 11 & 11 & 11 & 7 & 3 \\
\hline Solvent-extracted soybean meal & 87 & 87 & 87 & 87 & 77 & 68 \\
\hline Solvent-extracted canola meal & 69 & 69 & 69 & 69 & 80 & 92 \\
\hline Prilled palm fat $^{3}$ & 30 & 15 & - & - & - & - \\
\hline Sunflower oil ${ }^{4}$ & - & 15 & 30 & 30 & 30 & 30 \\
\hline Limestone & 10 & 10 & 10 & 10 & 11 & 11 \\
\hline Salt & 3 & 3 & 3 & 3 & 3 & 3 \\
\hline Sodium bicarbonate & 13 & 13 & 13 & 13 & 13 & 13 \\
\hline Mineral and vitamin premix ${ }^{5}$ & 4 & 4 & 4 & 4 & 4 & 4 \\
\hline Ruminal-protected methionine ${ }^{6}$ & 1 & 1 & 1 & 1 & 1 & 1 \\
\hline \multicolumn{7}{|l|}{ Chemical composition (g/kg of DM) } \\
\hline $\mathrm{OM}$ & 911 & 909 & 912 & 919 & 910 & 912 \\
\hline $\mathrm{CP}$ & 167 & 169 & 164 & 161 & 160 & 164 \\
\hline $\mathrm{ADF}$ & 205 & 199 & 210 & 203 & 215 & 252 \\
\hline NDF & 293 & 282 & 306 & 304 & 326 & 357 \\
\hline Starch & 200 & 194 & 193 & 185 & 156 & 141 \\
\hline Total fatty acids (FA) & 71.2 & 73.5 & 68.0 & 65.0 & 65.4 & 66.3 \\
\hline \multicolumn{7}{|l|}{ FA composition (g/100 g of FA) } \\
\hline 16:0 & 49.3 & 35.8 & 18.4 & 16.2 & 15.9 & 15.2 \\
\hline $18: 0$ & 4.11 & 4.23 & 4.25 & 4.82 & 4.63 & 4.45 \\
\hline cis-9 18:1 & 16.1 & 18.8 & 21.6 & 24.1 & 23.8 & 23.8 \\
\hline $18: 2 n-6$ & 19.5 & 30.2 & 43.4 & 42.5 & 42.2 & 43.0 \\
\hline $18: 3 n-3$ & 4.63 & 4.27 & 4.79 & 4.53 & 5.02 & 5.40 \\
\hline
\end{tabular}

${ }^{1}$ Treatments consisted of low-forage [forage-to-concentrate ratio (F:C) of 39:61] diets containing $30 \mathrm{~g} / \mathrm{kg}$ of DM of prilled palm fat (LF-P), sunflower oil (LF-S), or an equal mixture of both fats (LF-PS).

${ }^{2}$ Treatments consisted of low-forage (F:C of 39:61; LF-S), medium-forage (F:C of 44:56; MF-S), or high-forage (F:C of 48:52; HF-S) diets containing $30 \mathrm{~g} / \mathrm{kg}$ of DM of sunflower oil.

${ }^{3}$ Fractionated refined palm oil containing (g/100 g of total FA) 16:0 (74.4), 18:0 (4.88), cis-9 18:1 (15.1), 18:2n6 (2.82), and 18:3n-3 (0.11; RumiFat R100, Ecolex, Selangor, Malaysia).

${ }^{4}$ Refined sunflower oil containing (g/100 g of total FA) 16:0 (8.21), 18:0 (4.04), cis-9 18:1 (23.1), 18:2n-6 (58.3), and 18:3n-3 (2.96; Oila-Golrang Pakhsh Co., Tehran, Iran).

${ }^{5}$ Declared to contain (g/kg of DM) Ca (180), P (70), Mg (30), Na (50), Fe (4), Cu (3), Zn (3), Mn (5), I (0.1), Co (0.1), Se (0.02), antioxidant (0.4); (IU/g), retinyl acetate (400), cholecalciferol (100), and D- $\alpha$ tocopherol acetate $(0.2)$.

${ }^{6}$ Ruminal-protected methionine (Methioplus, Soda Feed Ingredients, Monaco). 
transferred to a $15-\mathrm{mL}$ glass test tube and centrifuged at 3,000 $\times g$ (model K-2042; Centurion Scientific Ltd., West Sussex, UK) for $15 \mathrm{~min}$ at $4^{\circ} \mathrm{C}$. A $1-\mu \mathrm{L}$ aliquot of upper layer was injected into a GC (PU 4410 gas chromatograph; Philips, London, UK) equipped with an injector at $180^{\circ} \mathrm{C}$, a flame-ionization detector at $180^{\circ} \mathrm{C}$, and a packed column $(2-\mathrm{m}$ length $\times 46-\mathrm{mm}$ inner diameter, glass containing $10 \%$ polyethylene glycol-20 M on 60/80 mesh Chromosorb W; Sigma-Aldrich). The temperature of the $\mathrm{GC}$ oven was maintained at $70^{\circ} \mathrm{C}$ for $1 \mathrm{~min}$, increased to $90^{\circ} \mathrm{C}$ at a rate of $9^{\circ} \mathrm{C} / \mathrm{min}$ and held for $1 \mathrm{~min}$, and again increased at the rate of $10^{\circ} \mathrm{C} / \mathrm{min}$ to a final temperature of $160^{\circ} \mathrm{C}$ and held for $10 \mathrm{~min}$. Gas flow rates were 30,33 , and $300 \mathrm{~mL} / \mathrm{min}$ for hydrogen (carrier), nitrogen, and compressed air, respectively.

Data were analyzed as a randomized complete block design, with a model that included the fixed effect of treatment, the fixed effect of covariate, the random effect of cow within treatment, and the random effect of block using PROC MIXED of SAS (SAS 9.2; SAS Institute, Cary, NC). Dry matter intake, milk fat concentration, and milk fat yield were used as covariates for the analyses of rumen fermentation, milk OBCFA concentration, and milk OBCFA yield variables, respectively. Residual distributions were assessed for normality using the Kolmogorov-Smirnov test with the PROC UNIVARIATE of SAS and no data were transformed before analyses. Influential data were inspected using distribution of Cook's distance statistic with the PROC MIXED of SAS and no data were removed before analyses. Error sums of squares were separated into single degree of freedom contrasts to test for the significance of linear and quadratic effects of replacement of PPF with SO (experiment 1) or increases in dietary F:C (experiment 2). Least squares means are reported and linear and quadratic effects of treatments were declared significant at $P \leq 0.05$, and tendencies were declared at $0.05<P \leq 0.10$.

Associations among ruminal VFA molar proportions and milk OBCFA concentrations were evaluated by the loading plots of PCA, using individual cow observations $(\mathrm{n}=48)$. The PCA analysis was performed based on the correlation matrix and varimax method for the orthogonal rotation of principal components (PC) using PASW Statistics 18 (Release 18.0.0, SPSS Inc., Chicago, IL; Massart et al., 1988). Final PC were extracted from the initial PC based on 2 criteria, namely (1) PC that had an eigenvalue greater than 1 (Kaiser's criterion) and (2) PC that had more than 2 high loadings (correlation coefficient between the original variable and the $\mathrm{PC}$ of more than $|0.6|$, indicating an original variable is influential in forming the new variable; Massart et al., 1988).
The first 3 significant $\mathrm{PC}$ cumulatively explained $71.9 \%$ (40.6, 18.5, and $12.8 \%$ in $\mathrm{PC} 1, \mathrm{PC} 2$, and $\mathrm{PC} 3$, respectively) of the total variation in molar proportions of ruminal acetate and propionate and concentrations of some milk OBCFA (Figure 1). Ruminal butyrate molar proportion and milk 13:0 anteiso concentration were included in the initial PCA analysis, but these data were subsequently excluded from the model because they did not have the eligible model fit criteria.
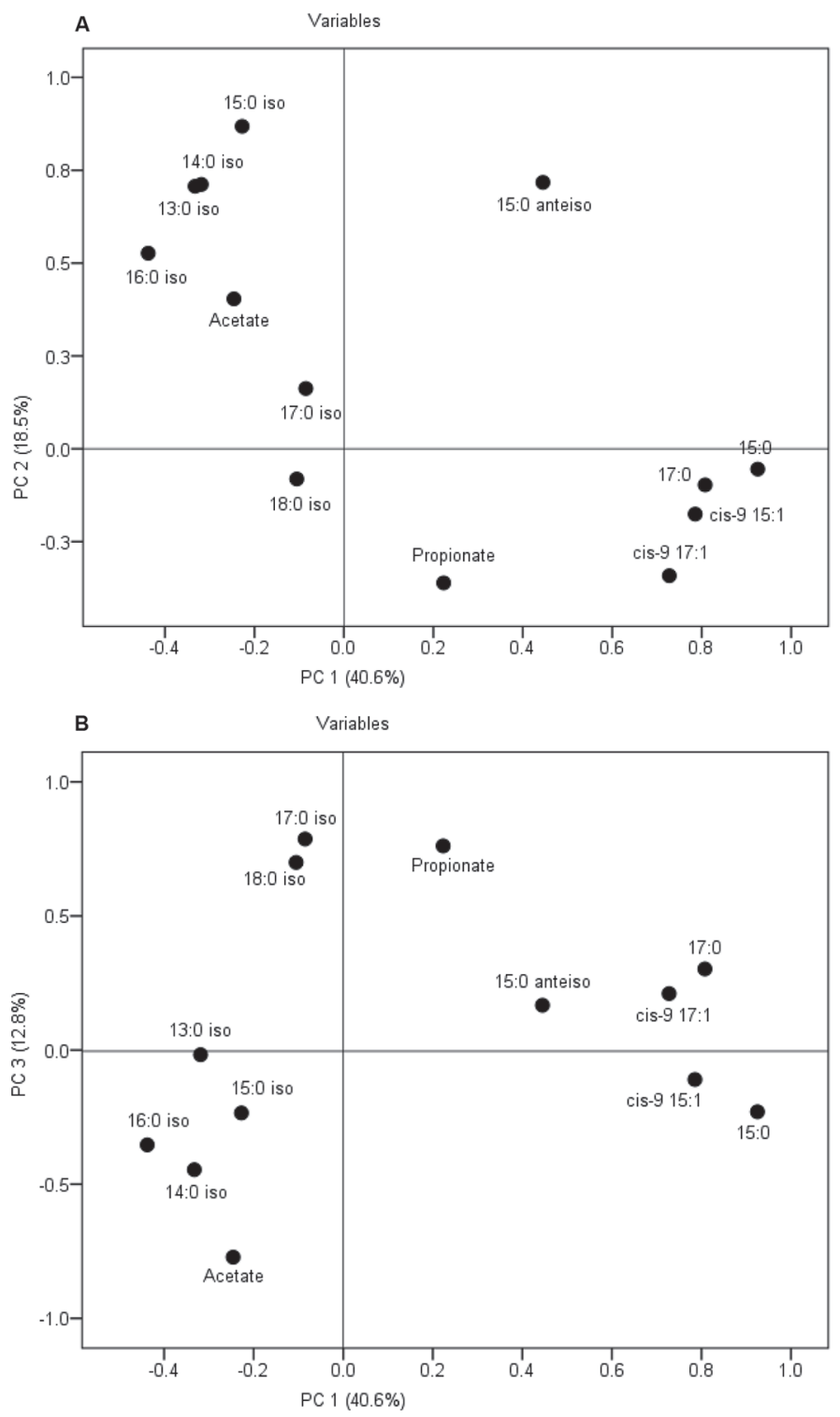

Figure 1. Loading plots of principal component (PC) 1 versus $\mathrm{PC} 2$ (A) and PC1 versus PC3 (B) describing the relationships among molar proportions of individual ruminal VFA and concentrations of odd- and branched-chain fatty acids in milk fat derived from PC analysis of 13 measured parameters from 48 lactating cows. The explained variance of each $\mathrm{PC}$ is given in parentheses. 
Table 2. Effects of replacement of prilled palm fat with sunflower oil in low-forage diets (experiment 1) or increasing forage-to-concentrate ratio (F:C) of diets containing sunflower oil (experiment 2) on ruminal fermentation characteristics in lactating cows

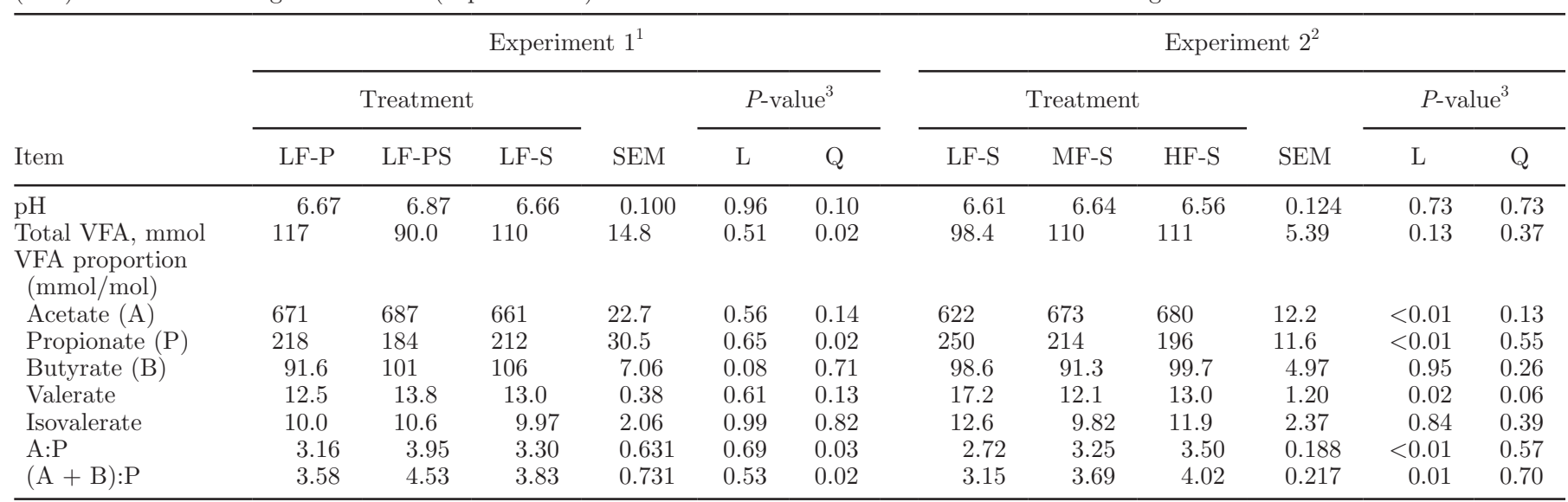

${ }^{1}$ Treatments consisted of low-forage (F:C of 39:61) diets containing $30 \mathrm{~g} / \mathrm{kg}$ of DM of prilled palm fat (LF-P), sunflower oil (LF-S), or an equal mixture of both fats (LF-PS).

${ }^{2}$ Treatments consisted of low-forage (F:C of 39:61; LF-S), medium-forage (F:C of 44:56; MF-S), or high-forage (F:C of 48:52; HF-S) diets containing $30 \mathrm{~g} / \mathrm{kg}$ of $\mathrm{DM}$ of sunflower oil.

${ }^{3}$ Significance of linear $(\mathrm{L})$ and quadratic $(\mathrm{Q})$ components of the response to replacement of prilled palm fat with sunflower oil in low-forage diet (experiment 1) or increasing F:C of diets containing sunflower oil (experiment 2).

Improving nutritional health aspects of milk would be beneficial for global food security and would enhance the sustainability of dairy production. We evaluated dietary unsaturated fat supplementation to improve milk FA quality. This feeding practice in high-concentrate diets often results in a decrease in milk fat concentration and secretion, and one of possible ways to alleviate milk fat depression is to increase forage proportions in diets (Harvatine et al., 2009). Under current experimental conditions, replacing PPF with SO in low-forage diets decreased milk fat concentration significantly $(P<0.01)$ and yield numerically $(P=0.12)$, whereas replacing the concentrate ingredients with forages in diets containing $\mathrm{SO}$ increased $(P<0.05)$ both milk fat concentration and yield (Vazirigohar et al., 2014). Decreases in milk fat secretion were associated with increases in milk trans-10,cis-12 CLA, trans-10 18:1, and trans-9,cis-11 CLA concentrations (Vazirigohar et al., 2014). These specific ruminal FA biohydrogenation intermediates equivocally (trans-10 18:1 and trans9,cis-11 CLA) or unequivocally (trans-10,cis-12 CLA) reduce lipogenesis in the mammary gland (Harvatine et al., 2009; Shingfield et al., 2010).

Replacement of PPF with SO had no effect on ruminal $\mathrm{pH}$, but quadratically decreased total VFA concentrations (Table 2). Effects of including plant oils rich in 18:2n-6 in dairy cow diets on total or individual ruminal VFA are not consistent. Griinari et al. (1998) replaced saturated fat with corn oil at $40 \mathrm{~g} / \mathrm{kg}$ of DM in low-fiber diets and reported a decrease in total VFA concentration and molar proportion of acetate in the rumen. Kargar et al. (2012) compared hydrogenated palm oil with yellow grease oil enriched 18:2n-6 (at 20 $\mathrm{g} / \mathrm{kg}$ of $\mathrm{DM}$ ) in high-concentrate diets and found no effects on total ruminal VFA and acetate or propionate molar proportions, and an increase in butyrate with yellow grease oil diet. In experiment 1 , cows receiving the diet containing an equal mix of PPF and SO had the lowest total VFA concentration and molar proportion of propionate in the rumen (Table 2). The quadratic changes of several iso FA in milk (14:0 iso, 15:0 iso, 16:0 iso, and total even iso FA; Table 3) in this experiment suggest, at least in part, changes in ruminal microbial communities and therefore microbial lipids and VFA pattern (Fievez et al., 2012). In a previous study, inclusion of unsaturated fat sources (at $50 \mathrm{~g} /$ $\mathrm{kg}$ of DM) in grass silage diets also changed numerous ruminal microbiota and fermentation function (Bayat et al., 2018).

Replacing PPF with SO linearly decreased concentration and yield of 13:0 anteiso, as well as yields of 15:0 anteiso and total anteiso FA in milk (Table 3). These results can partly be explained by decreases in amylolytic bacteria, which are enriched anteiso FA (Fievez et al., 2012). In the loading plot of PC1 versus PC3, 15:0 anteiso was located close to ruminal propionate and milk 17:0 (Figure 1), which can also imply the ruminal amylolytic bacterial origin of this FA in milk. It is indicated that ruminal bacteria, particularly cellulolytic bacteria that have high levels of iso FA (Fievez et al., 2012), are negatively affected by dietary PUFA (Patra and Yu, 2013). As the concentrations and yields 


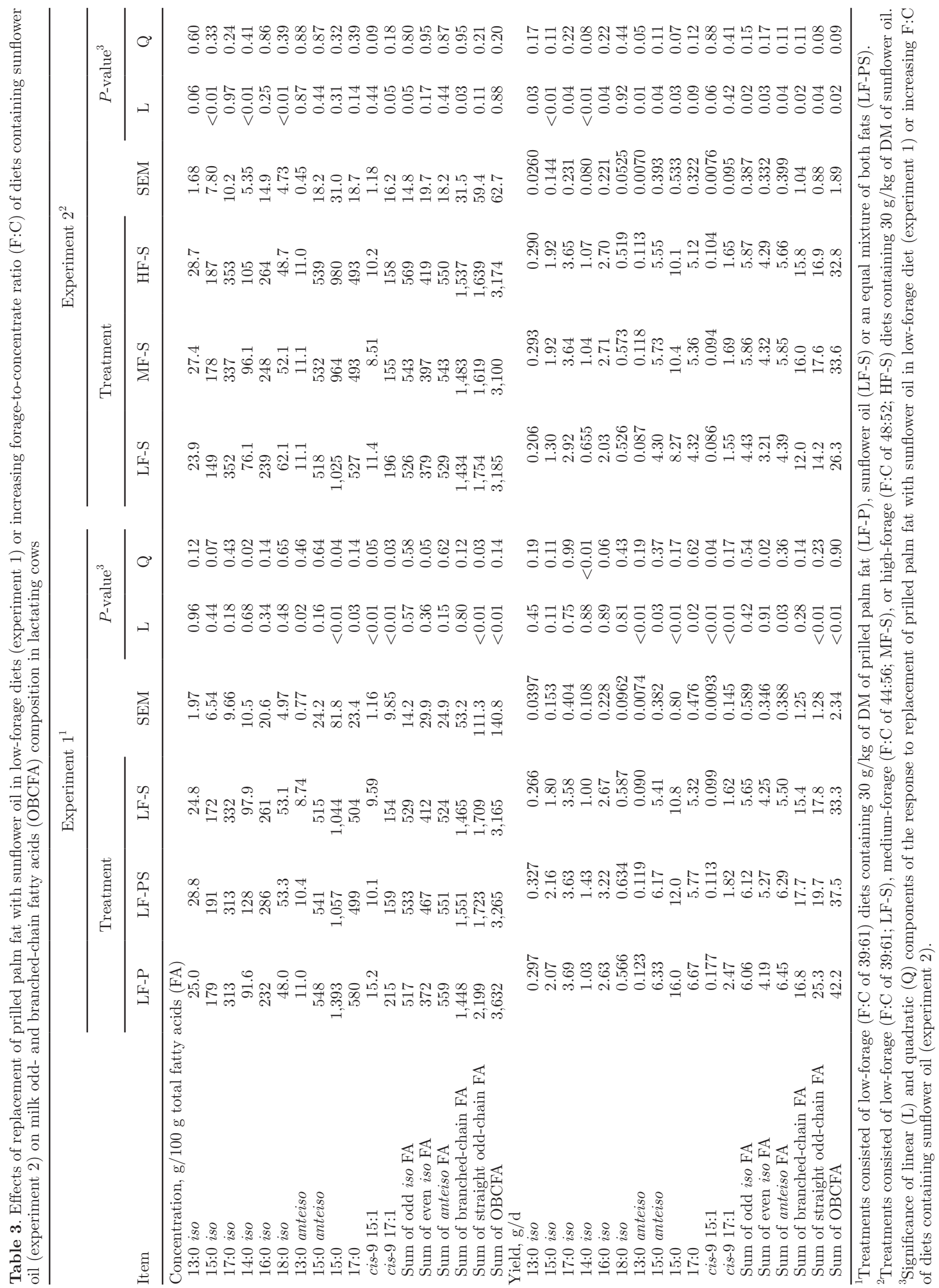


of milk 14:0 iso and total even iso FA, concentration of 15:0 iso, and yield of 16:0 iso in cows receiving the diet containing an equal mix of PPF and SO were the highest (Table 3), it seems that SO supplement at the current inclusion rate $(15 \mathrm{~g} / \mathrm{kg}$ of DM) had unlikely toxic effects on major ruminal cellulolytic bacterial populations. Replacement of PPF with SO linearly decreased concentrations and yields of milk 15:0, 17:0, cis-9 15:1, cis-9 17:1, and total straight odd-chain FA (Table 3). Reductions in milk 15:0 and 17:0 can be, in part, explained by the reduction of amylolytic bacteria in the rumen, which are propionate producers (supported by decreases in molar propionate proportion; Table 2) and enriched straight odd-chain FA (Fievez et al., 2012). Straight odd-chain FA in milk originate from both ruminal amylolytic bacteria and de novo synthesis in the mammary gland (Fievez et al., 2012). Direct comparisons have also shown that the secretion of 15:0 and 17:0 in milk exceeds (approximately 50\%) the flow of these FA at the duodenum (Fievez et al., 2012). Therefore, decreases of 15:0 and 17:0 in milk can be partly related to greater availability of 18-carbon FA inhibiting the activity of acetyl-CoA carboxylase in the mammary gland including trans-10,cis-12 CLA (Shingfield et al., 2010; Fievez et al., 2012; Vazirigohar et al., 2014). Synthesis of FA de novo accounts for all milk 4:0 to 12:0, most of the 14:0 (approximately 95\%), and about $50 \%$ of $16: 0$; whereas all 18 -carbon and longerchain FA are thought to be derived from circulating plasma lipids (Shingfield et al., 2010). In the loading plot of PC1 versus PC3, milk 17:0 and cis-9 17:1 were located in the same quadrant as the loading of ruminal propionate (northeast quadrant), whereas 15:0 and cis9 15:1 were separated by PC3 (southeast quadrant; Figure 1). These associations reveal that a larger portion of 15:0 in milk likely originates from de novo synthesis compared with that for 17:0. Evidence exists that the majority of cis-9 17:1 in milk arises from the action of stearoyl-CoA desaturase on 17:0 in the mammary gland (Fievez et al., 2012). Therefore, decreases in the availability of 17:0 in the mammary gland when SO replaced PPF offers an explanation for the concomitant lower milk cis-9 17:1 secretion. Milk cis-9 15:1 decreased by replacement of PPF with SO, and 15:0, 17:0, cis-9 15:1, and cis-9 17:1 had high loadings on PC1 (more than $|0.6|$; Figure 1), suggesting that most cis-9 15:1 secreted in milk is also synthesized endogenously from 15:0 in the mammary gland.

Increasing forage proportions in diets containing SO linearly increased the concentrations and yields of milk 13:0 iso, 14:0 iso, 15:0 iso and total odd iso FA, as well as yields of 16:0 iso, 17:0 iso and total even iso FA (Table 3 ). These responses could be attributed to increases in the abundance of ruminal cellulolytic bacteria, which are acetate producers (as supported by increases in molar acetate proportion; Table 2) and enriched odd- or even-chain iso FA (Fievez et al., 2012). Increasing dietary F:C had no effect on 17:0 iso concentration or decreased concentration and yield of milk 18:0 iso (Table $3)$. In the loading plots, the cluster of 13:0 iso, 14:0 iso, 15:0 iso, and 16:0 iso was separated from 17:0 iso and 18:0 iso cluster (Figure 1), which implies the different origins of the FA in these 2 groups. A strong correlation has also been noted between concentrations of 14:0 iso, 15:0 iso, and 16:0 iso FA in mixed ruminal bacteria (Bas et al., 2003). Moreover, milk secretion of 17:0 iso is noted in excess of duodenal flow of this FA (Fievez et al., 2012). Greater proportions of forages in diets containing SO had no effect on 13:0 anteiso, 15:0 anteiso, 15:0, 17:0, total anteiso FA, or total straight odd-chain FA concentrations in milk, but increased yields of these FA. Previous studies found similar responses on milk fat anteiso FA concentrations in cows fed higher levels of forages in diets supplementing with (Saliba et al., 2014) or without (Patel et al., 2013) plant oils. Increases in the $\mathrm{F}: \mathrm{C}$ in diets containing SO lowered concentration and yield of milk trans-10,cis-12 CLA (Vazirigohar et al., 2014), a potent inhibitor of de novo FA synthesis in the mammary gland (Shingfield et al., 2010); hence, it is possible that the increased yields of milk 15:0 and 17:0 were related to increases in endogenous synthesis of these FA in the mammary gland (Shingfield et al., 2010; Fievez et al., 2012).

In the current study, as illustrated in the loading plots (Figure 1), ruminal acetate molar proportion associated with milk iso FA <17-carbon, whereas ruminal propionate associated with milk straight odd-chain FA (15:0 and 17:0) and their desaturation products (cis-9 15:1 and cis-9 17:1) in cows fed diets containing supplemental fats. The results were similar to the associations observed in other studies examining diets without fat supplements (Fievez et al., 2012). In our study, ruminal fluid samples were collected via stomach tubing once per cow, which could show weak relations between ruminal VFA molar proportions and milk OBCFA concentrations. However, it has been shown that ruminal fermentation parameters and microbial composition are usually similar for samples collected via oral stomach tubing, rumenocentesis, or ruminal cannula (Lodge-Ivey et al., 2009; Shen et al., 2012). The molar proportions of ruminal VFA are also usually less sensitive to site and time of sampling than ruminal VFA production rate (Morvay et al., 2011). In previous studies, ruminal butyrate proportion were predicted by milk 15:0 anteiso and 15:0 concentrations (refer to Fievez et al., 2012) or 14:0 iso, 15:0, 
and 17:0 (Bhagwat et al., 2012). In our study, ruminal butyrate had no associations with any of milk OBCFA composition in results of PCA and showed a negative correlation ( $\mathrm{r}=-0.33, P=0.02, \mathrm{n}=48)$ just with milk 13:0 anteiso concentration (not with any other milk OBCFA) in results of Pearson correlation analysis (data not shown). Results of PCA also implied that the relationships between ruminal molar proportion of acetate and milk OBCFA concentrations were stronger than molar proportion of propionate, as the close locations of ruminal acetate and milk iso FA (13:0 iso, 14:0 iso, 15:0 iso, and 16:0 iso), rather than the far locations of ruminal propionate and straight odd-chain FA (15:0 and 17:0) were observed in the loading plots (Figure 1). Although, a dual origin (ruminal microbial and endogenous synthesis) of straight odd-chain FA in milk might be at least a part of the possible reason for the weaker relationships between ruminal propionate and milk OBCFA compared with the acetate, evaluation of several published VFA prediction models based on dietary factors have also shown that acetate predictions were better than propionate or butyrate predictions (Morvay et al., 2011). This might suggest that ruminal acetate variations can be better defined by either milk OBCFA or feed characteristics compared with propionate or butyrate variations. These differences can be partly related to the variation in fractional absorption rate of each acid from the rumen and their metabolism by the gut epithelium, especially butyrate and to a lesser extent propionate, and by the liver (Dijkstra, 1994).

In conclusion, our study suggests that complete replacement of a fat supplement rich in 16:0 with an unsaturated fat source rich in $18: 2 \mathrm{n}-6$ at $30 \mathrm{~g} / \mathrm{kg}$ of $\mathrm{DM}$ in low-forage diets is not an effective strategy to enhance bioactive branched-chain FA in milk, rather this feeding practice lowers yields of milk 13:0 anteiso and 15:0 anteiso; however, including an equal mixture of both fats (at $15 \mathrm{~g} / \mathrm{kg}$ of DM of each) in low-forage diets increases secretion of 14:0 iso and 16:0 iso in milk. Increasing forage proportions in diets containing a fat supplement rich in 18:2n-6 enrich milk with numerous branched-chain FA, including 13:0 iso, 14:0 iso, 15:0 iso, 16:0 iso, 17:0 iso, 13:0 anteiso, and 15:0 anteiso. The potential of using milk OBCFA concentrations to predict ruminal molar proportion of acetate is stronger than ruminal propionate or butyrate for diets containing supplemental fats in lactating cows.

\section{ACKNOWLEDGMENTS}

The $\mathrm{PhD}$ research of Mina Vazirigohar is partly supported by the University of Tehran (Alborz, Iran), Iran National Science Foundation (Tehran, Iran), Natural
Resources Institute Finland (Jokioinen, Finland), and Swedish University of Agricultural Sciences (Umeå, Sweden). The authors cordially dedicate this article to the memories of late Kevin J. Shingfield for his kind advice on the lipid analysis.

\section{REFERENCES}

Alfonso-Avila, A. R., E. Baumann, É. Charbonneau, P. Y. Chouinard, G. F. Tremblay, and R. Gervais. 2017. Interaction of potassium carbonate and soybean oil supplementation on performance of early-lactation dairy cows fed a high-concentrate diet. J. Dairy Sci. 100:9007-9019.

Bas, P., H. Archimède, A. Rouzeau, and D. Sauvant. 2003. Fatty acid composition of mixed-ruminal bacteria: Effect of concentration and type of forage. J. Dairy Sci. 86:2940-2948.

Baumann, E., P. Y. Chouinard, Y. Lebeuf, D. E. Rico, and R. Gervais. 2016. Effect of lipid supplementation on milk odd- and branchedchain fatty acids in dairy cows. J. Dairy Sci. 99:6311-6323.

Bayat, A. R., I. Tapio, J. Vilkki, K. J. Shingfield, and H. Leskinen. 2018. Plant oil supplements reduce methane emissions and improve milk fatty acid composition in dairy cows fed grass silage-based diets without affecting milk yield. J. Dairy Sci. 101:1136-1151.

Bhagwat, A. M., B. De Baets, A. Steen, B. Vlaeminck, and V. Fievez. 2012. Prediction of ruminal volatile fatty acid proportions of lactating dairy cows based on milk odd- and branched-chain fatty acid profiles: New models, better predictions. J. Dairy Sci. 95:3926-3937.

Dijkstra, J. 1994. Production and absorption of volatile fatty acids in the ruminal. Livest. Prod. Sci. 39:61-69.

Fievez, V., E. Colman, J. M. Castro-Montoya, I. Stefanov, and B. Vlaeminck. 2012. Milk odd- and branched-chain fatty acids as biomarkers of rumen function-An update. Anim. Feed Sci. Technol. $172: 51-65$

French, E. A., S. J. Bertics, and L. E. Armentano. 2012. Ruminal and milk odd- and branched-chain fatty acid proportions are minimally influenced by ruminal volatile fatty acid infusions. J. Dairy Sci. 95:2015-2026.

Griinari, J. M., D. A. Dwyer, M. A. McGuire, D. E. Bauman, D. L. Palmquist, and K. V. V. Nurmela. 1998. Trans-octadecenoic acids and milk fat depression in lactating dairy cows. J. Dairy Sci. 81:1251-1261.

Halmemies-Beauchet-Filleau, A., T. Kokkonen, A.-M. Lampi, V. Toivonen, K. J. Shingfield, and A. Vanhatalo. 2011. Effect of plant oils and camelina expeller on milk fatty acid composition in lactating cows fed diets based on red clover silage. J. Dairy Sci. 94:4413-4430.

Harvatine, K. J., Y. R. Boisclair, and D. E. Bauman. 2009. Recent advances in the regulation of milk fat synthesis. Animal 3:40-54.

Kargar, S., G. R. Ghorbani, M. Alikhani, M. Khorvash, L. Rashidi, and D. J. Schingoethe. 2012. Lactational performance and milk fatty acid profile of Holstein cows in response to dietary fat supplements and forage:concentrate ratio. Livest. Sci. 150:274-283.

Lock, A. L., C. L. Preseault, J. E. Rico, K. E. DeLand, and M. S. Allen. 2013. Feeding a C16:0-enriched fat supplement increased the yield of milk fat and improved conversion of feed to milk. J. Dairy Sci. 96:6650-6659.

Lodge-Ivey, S. L., J. Browne-Silva, and M. B. Horvath. 2009. Technical note: Bacterial diversity and fermentation end products in rumen fluid samples collected via oral lavage or rumen cannula. J. Anim. Sci. 87:2333-2337.

Massart, D. L., B. G. M. Vandeginste, S. N. Deming, Y. Michotte, and L. Kaufman. 1988. Principal components and factor analysis. Pages 339-369 in Chemometrics. A Textbook. Elsevier Science, Amsterdam, the Netherlands.

Morvay, Y., A. Bannink, J. France, E. Kebreab, and J. Dijkstra. 2011. Evaluation of models to predict the stoichiometry of volatile fatty 
acid profiles in rumen fluid of lactating Holstein cows. J. Dairy Sci. 94:3063-3080

Patel, M., E. Wredle, and J. Bertilsson. 2013. Effect of dietary proportion of grass silage on milk fat with emphasis on odd- and branched-chain fatty acids in dairy cows. J. Dairy Sci. 96:390-397.

Patra, A. K., and Z. Yu. 2013. Effects of coconut and fish oils on ruminal methanogenesis, fermentation, and abundance and diversity of microbial populations in vitro. J. Dairy Sci. 96:1782-1792.

Ran-Ressler, R. R., S. Bae, P. Lawrence, D. H. Wang, and J. T. Brenna. 2014. Branched-chain fatty acid content of foods and estimated intake in the USA. Br. J. Nutr. 112:565-572.

Saliba, L., R. Gervais, Y. Lebeuf, and P. Y. Chouinard. 2014. Effect of feeding linseed oil in diets differing in forage to concentrate ratio: 1. Production performance and milk fat content of biohydrogenation intermediates of $\alpha$-linolenic acid. J. Dairy Res. 81:82-90.

Shen, J. S., Z. Chai, L. J. Song, J. X. Liu, and Y. M. Wu. 2012. Insertion depth of oral stomach tubes may affect the fermentation parameters of ruminal fluid collected in dairy cows. J. Dairy Sci 95:5978-5984.

Shingfield, K. J., L. Bernard, C. Leroux, and Y. Chilliard. 2010. Role of trans fatty acids in the nutritional regulation of mammary lipogenesis in ruminants. Animal 4:1140-1166.

Shingfield, K. J., M. Bonnet, and N. D. Scollan. 2013. Recent developments in altering the fatty acid composition of ruminant derived foods. Animal 7:132-162.

Vazirigohar, M., M. Dehghan-Banadaky, K. Rezayazdi, S. J. Krizsan, A. Nejati-Javaremi, and K. J. Shingfield. 2014. Fat source and dietary forage-to-concentrate ratio influences milk fatty acid composition in lactating cows. Animal 8:163-174.

Vlaeminck, B., R. Gervais, M. M. Rahman, F. Gadeyne, M. Gorniak, M. Doreau, and V. Fievez. 2015. Postruminal synthesis modifies the odd- and branched-chain fatty acid profile from the duodenum to milk. J. Dairy Sci. 98:4829-4840. 